\title{
Characteristics and predictors of recidivist drink-drivers
}

\author{
Wickens, C. M., Flam-Zalcman, R., Mann, R. E., Stoduto, G., \\ Docherty, C., \& Thomas, R. K.
}

Version Post-Print/Accepted Manuscript

Citation Wickens, C. M., Flam-Zalcman, R., Mann, R. E., Stoduto, G., Docherty, (published version) C., \& Thomas, R. K. (2016). Characteristics and predictors of recidivist drink-drivers. Traffic Injury Prevention, 17, 564-572.

Publisher's Statement This is an Accepted Manuscript of an article published by Taylor \& Francis in Traffic Injury Prevention on January 13, 2016, available online: http://www.tandfonline.com/10.1080/15389588.2015.1125477.

How to cite TSpace items

Always cite the published version, so the author(s) will receive recognition through services that track citation counts, e.g. Scopus. If you need to cite the page number of the TSpace version (original manuscript or accepted manuscript) because you cannot access the published version, then cite the TSpace version in addition to the published version using the permanent URI (handle) found on the record page. 


\title{
Running head: CHARACTERISTICS OF RECIDIVIST DRINK-DRIVERS
}

\section{Characteristics and Predictors of Recidivist Drink-Drivers}

\author{
Christine M. Wickens ${ }^{1,2}$, Rosely Flam-Zalcman ${ }^{1}$, Robert E. Mann ${ }^{1,2}$, \\ Gina Stoduto ${ }^{1}$, Chloe Docherty ${ }^{1}$ and Rita K. Thomas ${ }^{1}$ \\ 1 - Centre for Addiction and Mental Health, Toronto, Ontario, Canada \\ 2 - Dalla Lana School of Public Health, University of Toronto, Toronto, Ontario, Canada
}

Correspondence concerning this article should be addressed to:

Dr. Christine M. Wickens

Centre for Addiction and Mental Health

Social and Epidemiological Research Department

33 Russell Street

Toronto, Ontario M5S 2S1

Phone: 416-535-8501 ext. 34711

Fax: 416-595-6899

Email: Christine.Wickens@camh.ca 


\begin{abstract}
Objective: The current study compared characteristics of nonrecidivist versus recidivist drink-drivers and of recidivists in their first versus second appearance at Back on Track (BOT), the remedial measures program for impaired drivers in Ontario, Canada.

Methods: Information from 59,134 convicted drivers who participated in BOT between 2000 and 2010 was examined to identify drivers who completed the program a second time following reconviction.

Results: A total of 586 recidivists were identified. Compared to nonrecidivist drivers, recidivists at first attendance were more likely to be male and had higher scores on measures of alcohol dependence and adverse legal consequences of substance use. Compared to nonrecidivist drivers, recidivists at second attendance were significantly older, had a higher income, were more likely to be retired and were less likely to be employed part-time. They had fewer legal problems. Recidivists reported fewer drinking days, and fewer drinks per occasion but greater use of benzodiazepines than nonrecidivists and had higher scores on a measure of future risk of alcohol- and drug-related problems. Comparison of recidivists' characteristics at first versus second attendance confirmed many of these findings, with second-time recidivists reporting fewer drinks per drinking day and greater use of benzodiazepines and having higher scores on a measure of future substance use problems than first-time recidivists.

Conclusions: Results suggest that identification of drivers at increased risk of recidivism may be possible at first program attendance by examining indicators of increased alcohol-related problems. In addition, recidivists appear to show a greater readiness to change at second attendance. Implications for remedial program development and recommendations for future research are discussed.
\end{abstract}

Key words: Alcohol, drugs, interventions, drink-drivers 


\section{Introduction}

\section{Outcomes of remedial programs}

The aim of remedial programs is to reduce risk behaviors and the risk of drink-driving recidivism and collisions among those previously convicted with a drink-driving offense. Not all remedial programs are the same; they differ based on the approach taken to rehabilitation (Health Canada 2004; Mann et al. 1983). Education programs inform participants about safe drinking levels, the effects of alcohol on the body, safe driving techniques, and so on; drinking problems, whether present or not, are not a direct focus of the program. Treatment programs are aimed to reduce drinking problems. There is well-documented evidence for the efficacy of both education- and treatmentfocused remedial programs. Randomized experimental trials have identified beneficial effects on knowledge, attitudes, drinking behavior, recidivism, collisions, and health-related measures, including mortality rates (e.g., Brown et al. 2010; Health Canada 2004; Mann et al. 1983, 1988, 1994; Wells-Parker et al. 1995).

Wells-Parker et al. (1995) conducted a meta-analysis of a large number of studies evaluating the impact of remedial programs (including active probation, education, psychological treatments, victim impact panels, and ignition interlocks) on drink-driving recidivism. Studies included in the meta-analysis compared different types of remedial programs to no remediation or to two or more forms of remediation. In their final analysis, the authors indicated that, on average, remedial programs reduced recidivism by 7 to $9 \%$ when compared to standard punitive models (such as license suspension), which offered no treatment at all. They also observed that when they looked at the impact of programs that combine education, treatment, and supervision, these programs reduced recidivism by an average of $24 \%$.

\section{Ontario's Back on Track program}

Back on Track (BOT) is the remedial measures program for impaired drivers in Ontario, Canada. Following a period of mandatory license suspension, completion of BOT is required. The structure of the program is determined by provincial mandate. Convicted drink-drivers are required to first complete an assessment that measures the severity of their substance-related problems. Individuals whose problems are determined to be less severe, as determined by the web-based assessment protocol, are assigned to an 8-h education workshop. Those whose problems are determined to be more severe are assigned to a 16-h treatment workshop. Finally, 6 months following completion of the 8-h or 16h workshop, the individual must complete a 30-min follow-up interview, typically by telephone. As a province-wide program mandated by the provincial government, BOT must meet high standards of program quality and consistency across the province. Quality assurance and evaluation activities are ongoing and include extensive monitoring of client satisfaction, program consistency, assessment processes, and client outcomes.

\section{Research on recidivist drivers}

The structure of the BOT program presents a number of evaluation opportunities, including an examination of the characteristics of drivers who return to the program; that is, recidivists who reenter the program. Though an understanding of recidivism and recidivist drivers is important to assess the impact of remedial programs and how they might be improved, few studies have addressed this issue. Previous research on recidivist drivers has examined program entry data for groups that do and do not recidivate over a particular follow-up interval. These studies have the important strength of examining the characteristics of all drivers who recidivate in terms of being caught or apprehended for a subsequent offense. However, as has been noted elsewhere, given that the chances of being caught 
are relatively low, even studies that are able to consider all individuals caught or convicted over a period of time are subject to important but poorly understood sources of bias.

In an early study from California, Peck et al. (1994) examined psychometric, biographical, drinking history, and driving record measures as predictors of 4-year recidivism in a sample of 7,316 drink-driving offenders in Sacramento County. Peck et al. (1994) found a large number of variables predicted recidivism, including preconviction driving record variables, sex, age, and intake diagnosis. However, program-related measures such as program assignment and progress did not affect recidivism rate. Peck et al. (1994) also examined program completion in a subgroup of participants (with those who dropped out or were expelled being considered noncompliant). Completion status was significantly predicted by demographic (age, income, education), driving record (moving convictions, suspensions, collisions) and criminal (property crimes) measures. Completion status also significantly predicted post-program collisions and recidivism rates.

Nochajski and Stasiewicz (2006) reviewed the literature on recidivist drink-drivers. Factors found to be associated with recidivism included being male, older, and not currently married. Other factors associated with recidivism included higher rates of collisions and traffic violations and more indications of psychopathology. Measures of substance use were not consistently associated with recidivism. The authors concluded that drink-driving offenders are a heterogeneous group and thus many factors are likely to be involved in processes leading to recidivism.

\section{Purpose of the current study}

This article will present an outcome evaluation examining recidivist drivers in the BOT program and will focus on two questions of interest. The first question asks what proportion of BOT drivers are repeat offenders; that is, What is the proportion of drivers who are repeat program participants? The second question is, What factors differentiate repeat program participants from those who do not become repeat program participants?

\section{What proportion of BOT drivers are repeat participants?}

The availability of the BOT administrative data set with its large number of program participants and rich source of information about participants at assessment and follow-up provides a unique resource to examine the characteristics of program drivers who reenter the program following an initial participation. No previous evaluations of remedial programs have been able to report on these results. One very interesting opportunity is to assess the proportion of the total group of BOT drivers who are return drivers and to compare this proportion to the numbers that might be expected based on experiences in other jurisdictions or certain assumptions about program effectiveness.

In terms of subsequent convictions, we do not yet have any information on the total number of BOT drivers who are convicted recidivists. However, information from other jurisdictions does provide estimates that can be used to generate some expectations about Ontario recidivism rates. In recent literature, recidivism rates for first offenders appear to range from approximately $2.5 \%$ (Rauch et al. 2010) to 10\% per year (Robertson et al. 2009). In one Canadian study, 23\% of a group of convicted drink-drivers were reconvicted over a follow-up period ranging from 24 to 45 months, suggesting a recidivism rate of approximately $8 \%$ per year (Weinrath 1997). Thus, a range of between 2.5 and $10 \%$ seems a reasonable estimate for the recidivism rate expected for BOT. Based on a sample of 59,134 offenders, and assuming no replacements and only considering first re-offenses, this would mean we might expect between 1,478 and 5,913 recidivists. Assuming that an estimated 60\% would attend BOT (a conservative estimate of 
the proportion of all offenders who have registered for BOT since the program's inception), we would expect between 887 and 3,548 reentrants. If the number of reentrants is larger than this, it may suggest that the program is failing in its goal of reducing recidivism; and conversely, if the number of reentrants is smaller than this, it would be consistent with a conclusion that the program is being successful in reducing recidivism rates.

\section{What are the characteristics of drivers who return to BOT?}

A review of the literature reveals no previous studies that have examined characteristics of drivers who have returned to a remedial program following recidivism or unsuccessful completion. However, several studies have compared the characteristics of recidivists versus nonrecidivists, and these data were reviewed by Macdonald and Mann (1996). These authors found that recidivist drivers consumed more alcohol and had more alcohol problems and also scored higher on psychological measures of hostility, sensation seeking, psychopathic deviance, mania, and depression. Based on these and other findings with recidivist drivers (e.g., Nochajski and Stasiewicz 2006; Peck et al. 1994), we predict that individuals who return to the program will be characterized by specific demographic factors (being male, older, and not married) and by higher levels of alcohol problems. This evaluation also provides the unique opportunity to compare recidivist drivers to nonrecidivists, at both their first participation in the remedial program and their second.

\section{Methods}

Registration, assessment and follow-up measures

Since 2000, all BOT program participants have been required to register for the program following their conviction for a drink-driving offense. Once registration is complete, they complete an assessment as the first step in completion of the program. The assessment consists of the Research Institute on Addictions Self-Inventory (RIASI; Nochajski 2002; Nochajski et al. 1995), the Alcohol Dependence Scale (ADS; Skinner and Horn 1984) and the Drug Abuse Screening Test (DAST; Skinner 1982). Both the ADS and DAST were developed using Ontario samples and are widely used among addictions professionals in the province working with drivers seeking treatment for substance abuse. The RIASI was developed by Nochajski and colleagues (e.g., Nochajski 2002; Nochajski et al. 1995) at the Research Institute on Addictions in Buffalo, New York, as an instrument designed specifically for use with drinkdrivers. The RIASI generates two scores, a total score (RIASI-T) based on the full instrument, and the recidivism score (RIASI-R). Eight factors have been identified within the RIASI, reflecting problem areas associated with alcohol use (Mann et al. 2009). In addition, several other measures are collected at assessment, including the Adverse Consequences of Substance Use Scale (ACSUS; Mann et al. 2006), measures of substance use in the previous 90 days, contacts with health (including addictions-related) and corrections services in the previous 90 days, and various demographic measures (e.g., age, gender). The average time taken to complete the assessment questionnaire was 60 min. The follow-up interview was performed after the driver successfully completed the education or treatment workshop and required an additional $30 \mathrm{~min}$.

The drivers included in the current analysis were the 59,134 individuals who completed the follow-up interview up to June 1, 2010. The majority of drivers (about 96\%) completed the follow-up within 7 months of participating in their assigned 8-h education or 16-h treatment workshop. Assignment to the education or treatment workshop is based on a threshold score being reached on the screening instruments. 
The sample was predominantly male (88\%). The drivers completed the program (assessment, education/treatment, follow-up) between November 1, 1999, and June 1, 2010. They reported an average age of 42 years and approximately $75 \%$ of all offenders in the sample were younger than 50 years old. They had achieved an average of 12 years of schooling and reported a mean income between $\$ 20,000$ and $\$ 49,999$. Most reported being married $(44.4 \%)$ or single $(35.8 \%), 72.1 \%$ reported being currently employed, $25.8 \%$ reported that they had had a previous drink-driving offense in addition to the present one; and $72.4 \%$ were assigned to the education program and $27.6 \%$ were assigned to the treatment program (see Table 1 for a summary of demographic characteristics by group).

\section{Planned analyses}

Demographic differences between the nonrecidivist and two recidivist groups were assessed using chi-square analyses. Independent-samples $t$ tests were used to compare the number of previous convictions, scores on the screening instruments, measures of consequences of substance use, and factor scores on the RIASI instrument across the three groups. A Bonferroni correction to the minimum probability value $(P$-value) required for statistical significance was applied to each set of analyses to control for familywise error.

\section{Results}

\section{Number of recidivists}

A total of 586 recidivist drivers and 58,548 nonrecidivist drivers were found in the database. The number of recidivists compares favorably to the range of 887 and 3,548 reentrants that might be expected based on existing data, as discussed in the Introduction. These results suggest that less than $1 \%$ of the drivers were recidivist drivers, in that they returned to the program again after completing it a first time. However, it is important to keep in mind that the expected number of reentrants was based on a small number of studies that included data from several jurisdictions that may have differing policies and circumstances that may affect recidivism rates differently than those in Ontario. Among the 586 identified recidivist drivers, the interval between their first and second attendance at BOT varied from a low of 51 days to a high of 8.72 years. The average interval between first and second attendance was 4.98 years (SD $=1.74$ years).

For purposes of comparisons that would shed light on recidivist attendees of BOT, we compared BOT drivers who were not recidivists to recidivists the first time they attended the program and to recidivists the second time they attended the program. We also compared data on recidivists the first time they attended the program to the data from the second time they attended the program to assess how they may have changed over time.

\section{Demographics}

Comparisons of recidivist to nonrecidivist drivers and of recidivist drivers on the two occasions they attended the program are summarized in Table 1. Chi-square analyses were conducted for seven demographic variables. To control for familywise error, a Bonferroni adjustment was introduced $(P=.05 / 7=.007)$, requiring a $P$-value of .007 for statistical significance. It can be seen that recidivist drivers, on their first attendance, were significantly more likely to be male. No significant differences between the groups were seen on measures of income, employment, or education or whether they were assigned to education or treatment programs.

Comparisons of recidivist drivers the second time they attended the program with nonrecidivists revealed some interesting differences. As expected, males were more likely to be in the recidivist group. However, this time, recidivist drivers were older than nonrecidivists. Although no differences in education were found, recidivist drivers 
on their second contact with the program had higher income levels, were more likely to be retired and less likely to be employed part-time, and were more likely to be assigned to the treatment program.

Comparisons of recidivists the first time versus the second time they attended the program confirmed some impressions garnered from the recidivist versus nonrecidivist comparisons above. Not surprisingly, recidivists were older on their second attendance and no differences in sex were seen. Although they did not differ on education, recidivists on their second attendance were less likely to be employed full-time or part-time; more likely to be unemployed, a student, or retired; and more likely to be assigned to the treatment program.

\section{Screening scores and previous convictions}

Table 2 provides independent-sample and paired-sample $t$ test comparisons for five variables related to screening measures and previous convictions. The Bonferroni correction for familywise error required a minimum $P$ value of $.01(P=.05 / 5=.01)$ for statistical significance. Compared to nonrecidivists, recidivists on first assessment had higher scores on the ADS and fewer previous driving while impaired (DWI) convictions. However, the two groups did not differ significantly on the RIASI-T or RIASI-R scale or on the DAST. On their second attendance at BOT, other differences emerged. The recidivists now had significantly higher scores on the RIASI-T and RIASI-R and again had significantly more DWI convictions than the nonrecidivists. The two groups did not differ on the ADS or the DAST. Comparing the recidivists on their first and second attendance at the program revealed some differences. On the second attendance, the recidivists had significantly higher RIASI-T scores, lower scores on the ADS and DAST, and significantly more previous convictions. It is interesting to note that the number of previous convictions rose by almost exactly 1 , which would be expected if the participants were accurately reporting previous convictions.

\section{Comparisons of consequences of substance use}

Table 3 presents comparisons of recidivists at first and second attendance and nonrecidivists on eight measures of consequences of substance use derived from the ACSUS questionnaire. The Bonferroni adjustment for familywise error required a minimum $P$-value of $.006(P=.05 / 8=.006)$ for statistical significance. Relative to nonrecidivists, recidivists at first attendance reported significantly more consequences related to legal problems but significantly fewer legal consequences at second attendance. Comparing recidivists on the two occasions they participated in the program revealed that when participating for the second time recidivists reported significantly fewer legal problems than when they attended for the first time. No significant differences on any other measures were seen.

\section{Comparisons on RIASI factors}

Table 4 presents comparisons of the three groups on the eight factor scores derived from the RIASI instrument. Familywise error was controlled by a Bonferroni corrected minimum $P$-value of $.006(P=.05 / 8=.006)$. Interestingly, no significant differences were seen between nonrecidivists and recidivists at first attendance. When nonrecidivists were compared to recidivists the second time they attended the program, several differences emerged. On their second attendance, the recidivists had higher scores on the high-risk lifestyle, alcohol consequences, and interpersonal competence scales than nonrecidivists. Comparing the recidivists on their first and second attendance at the program revealed the same differences. On their second attendance, the recidivists had higher scores on the highrisk lifestyle, alcohol consequences, and interpersonal competence factors. 


\section{Comparisons on measures of substance use}

Table 5 presents comparisons across the three groups on 14 measures of substance use. The Bonferroni adjustment for familywise error required a conservative minimum $P$-value of $.004(P=.05 / 14=.004)$ for statistical significance; however, this correction had no impact on interpretation of the results. Interestingly, no significant differences in substance use measures were seen between nonrecidivists and recidivists at their first attendance. However, when nonrecidivists were compared to recidivists on their second attendance, several differences were seen. Recidivists on their second attendance reported fewer drinks per drinking day, fewer days drinking, and more days using benzodiazepines. When recidivists were compared on their first and second attendance at the program, some differences again emerged. On their second occasion attending the program, recidivists reported significantly fewer drinks per drinking day and significantly more days using benzodiazepines.

\section{Discussion}

\section{Limitations of this work}

Though this report identified important differences between recidivist and nonrecidivist drivers of the BOT program and presents evidence for the effectiveness of BOT at reducing drink-driving recidivism, several limitations must be considered. First, these observations are restricted to individuals who chose to abide by mandatory relicensing requirements by completing the BOT program. This represents a selection bias (Campbell and Stanley 1967) and it means that any program effects on recidivism may be related to the specific nature of individuals who chose to participate and are not necessarily generalizable to the full population of convicted drink-drivers. Available evidence suggests that the "difficult to contact" group may be more likely to have more serious problems (e.g., Mann et al. 2002). If this is the case, it may be possible that this group may be less likely to benefit from BOT, resulting in higher recidivism rates. Nonetheless, available data suggest that more than $50 \%$ of eligible individuals choose to participate in BOT, and this participation rate is one of the highest in Canada (Smart 2007). Second, the results are based on selfreport surveys, including measures of substance use and drink-driving behavior, which may be biased by socially desirable responding. However, reviews of behavioral self-reports of drug users have identified this approach as a valid and reliable means of measuring drug use and drug-related problems (e.g., Darke 1998; Winters et al. 1990). Third, the study adopted a quasi-experimental design, contrasting two nonrandomized and naturally occurring groups, which introduces possible contamination of the findings by extraneous or confounding variables and threatens the internal validity of the study. Nonetheless, in support of the study's validity, the results observed here are in general agreement with hypotheses, including one hypothesis that made specific predictions about the magnitude of the impact of BOT on drinking-driving recidivism. Fourth, the database of BOT participants likely does not capture all drink-driving recidivists, because not all incidents of drink-driving are detected by police or result in convictions, and many recidivists choose not return to the BOT program. Those who do not return to the program may differ in important ways from those who do. Future research should strive to link BOT data to driver record data in order to identify those who have committed a subsequent drink-driving offense but not returned to the program. Finally, the current analysis examined data across a wide time frame spanning approximately a 10-year period. This conservative approach maximized the likelihood of detecting program reattendance, ensuring the highest possible estimate of recidivism in the evaluation of the BOT program. However, there may be qualitative differences between those recidivists who return to BOT after a short interval versus those who return after a longer interval. Future analyses are 
needed to explore these qualitative differences and how they may impact the ability of various instruments to identify potential recidivists.

\section{Recidivism rate among BOT drivers}

Based on the number of BOT drivers who returned to the program again after completing it a first time, it is estimated that the recidivism rate among BOT participants is less than $1 \%$. This rate of recidivism is lower than what might be expected based on the limited existing data available from other remedial programs and suggests that BOT is having a positive impact on client recidivism. This finding is also consistent with previous evaluations of the BOT program showing positive change in substance use and related problems over the course of the program (Sharpley et al. 2007).

\section{Characteristics of BOT recidivists at first attendance}

When examining differences between recidivist drivers on their first attendance at the BOT program and nonrecidivist drivers, it was found that recidivists were more likely to be male. Males have traditionally been found to display more risk-taking behavior such as problematic alcohol and substance use, driving after drinking, driving after cannabis use, and aggressive driving (Begg et al. 2003; Greenfield and O'Leary 1999; Naimi et al. 2003; Wickens et al. 2012) and have been found in other studies to be more likely to be impaired driving recidivists (Marowitz 1998; Nochajski and Stasiewicz 2006). Other sociodemographic measures reflecting potential socioeconomic inequities (e.g., income, education) have also been identified as predictors of recidivism, suggesting that higher socioeconomic status is associated with less likelihood of repeat offending (Nochajski and Stasiewicz 2006). However, income, employment status, and education did not correlate with recidivism status at first attendance in the current analysis, suggesting that the relationship between socioeconomic status and recidivism may not hold at least as far as multiple program attendance is concerned.

It is also interesting to see that program assignment was not associated with recidivist status at first attendance. Previous analyses of BOT have shown that assignment to the education and treatment programs was associated with a specific benefit in drinking behavior at follow-up (Flam-Zalcman et al. 2013). Seeing no differences in recidivist status between those assigned to education and those assigned to treatment may suggest that treatment assignment did not alter recidivism risk. However, alternatively it may suggest that recidivism risk was similarly reduced by both programs for both types of individuals. More research to understand how program type affects various outcomes, perhaps employing a regression discontinuity design to see the beneficial effect of program assignment at the point of assignment, would be valuable here. (See Flam-Zalcman et al. 2013 for a previous application of regression discontinuity analysis to evaluation of BOT.) In addition, further research examining driver behavior measures of recidivism (e.g., collisions, charges, convictions) to see whether program measures can predict them would be very valuable.

\section{Characteristics of BOT recidivists at second attendance}

Comparing recidivists at the second appearance at the program with nonrecidivists provided an additional perspective on the recidivist group. At second attendance, recidivists were significantly older, had higher income, were more likely to be retired, and were less likely to be employed part-time. Some of these changes reflect the simple passage of time. Others, however, may reflect individuals who have become more engaged with their society 
and who may have more to lose from their conviction. Here, larger proportions of recidivists assigned to treatment may reflect recognition of alcohol problems by this group and an increasing honesty in reporting them.

These observations are generally confirmed in comparing the recidivists on their first and second program visits. They are older, of course, and interestingly, they were less likely to be employed and more likely to be students, unemployed, or retired. As suggested above, more drivers were assigned to the treatment program on their second contact with BOT, suggesting greater severity of alcohol- or substance-related problems among this group.

\section{Screening scores and previous convictions}

Data from screening scores and previous convictions provide an important picture of recidivist drivers. Interestingly, compared to nonrecidivists, recidivist drivers on their first visit had significantly higher scores on the ADS but not the RIASI-T, RIASI-R, or DAST. We have previously seen that all the screening measures predict 6month substance use and problem measures (Sharpley et al. 2007). However, these findings suggest that there may be a special role for the ADS in identifying potential recidivist drivers. In addition, interestingly, recidivist drivers on first visit had significantly fewer previous DWI convictions than nonrecidivists despite other research which might have predicted them to have more (e.g., Peck et al. 1994). We cannot be certain what is responsible for this observation. Although on average recidivist drivers on first visit were younger and thus may have had less driving exposure than nonrecidivists, this difference was not significant. Similarly, recidivists may have had less access to a vehicle and thus fewer opportunities to drive.

However, recidivists on their second appearance at the program showed other differences from nonrecidivists. These individuals then had higher scores on both RIASI measures but did not differ on the ADS. These findings might suggest that the RIASI may have more concurrent validity, whereas the ADS may have more predictive validity. However, this suggestion, though interesting, needs additional research before it can be accepted. In addition, recidivist drivers now had significantly more convictions than nonrecidivists. This might be expected given that they had experienced a second conviction in the interval. The comparison of recidivists at first and second appearance showed that at second appearance recidivists had significantly higher scores on the RIASI-T but lower scores on the ADS and DAST, providing some confirmation of the sensitivity of the RIASI to factors that affect recidivism status. As expected, recidivists also reported more DWI convictions at their second appearance.

Problem measures from the ACSUS also showed some ability to differentiate recidivists from nonrecidivists. On first attendance, recidivists showed higher levels of legal problems compared to nonrecidivists, whereas recidivists on second attendance demonstrated fewer legal problems. Consistent with this finding, when assessing change in the recidivist group from first to second attendance, the only significant change was a decline in legal problems. These data suggest that the measure of legal problems contained in the ACSUS may show promise in identifying those participants who may be more likely to become recidivists in the future.

None of the factor scores derived from the RIASI differentiated recidivists at first visit from nonrecidivists. However, a very different picture emerged when comparing recidivists at second attendance with nonrecidivists. Here, recidivists showed higher scores on several measures, including high-risk lifestyle, alcohol consequences, and interpersonal competence. These differences were confirmed by comparisons of recidivists at first and second program attendance: scores on the high-risk lifestyle, alcohol consequences, and interpersonal competence factors all 
increased significantly. These increases may reflect increasing acknowledgement of alcohol and drug problems and a willingness to deal with them.

Recidivists at first attendance did not differ from nonrecidivists on any measures of substance use. This lack of difference may suggest that substance use measures may not be good predictors of recidivism, but it may also suggest that individuals may not accurately report their substance use at assessment (e.g., Lapham et al. 2002) or that factors other than substance use may be more important determinants of recidivism. However, some differences in substance use measures were observed when comparing recidivists at second attendance with nonrecidivists. Interestingly, recidivists reported drinking fewer drinks per occasion and having fewer drinking occasions. This may reflect recognition of alcohol problems and attempts to address these problems, as suggested by some other findings here. It was also interesting to see that use of benzodiazepines was significantly higher among recidivists.

Benzodiazepines are drugs often used in the treatment of alcohol problems (Brands et al. 1998), and this higher level of use may suggest that an important portion of the recidivist population has engaged with treatment when they return to the program a second time. Comparisons of recidivists on first and second attendance provide some general confirmation of these observations, with fewer drinks per drinking day and higher use of benzodiazepines seen among those attending for the second time.

\section{Which measures are best at identifying potential recidivists?}

In this article, we have examined the association of sociodemographic characteristics, problem screening instruments and factors derived from them, previous convictions, substance use measures, and adverse consequences of substance use with recidivism status at first BOT attendance. These results suggest that the strongest predictors of reentry to the program were sociodemographic, problem screening, previous conviction, and adverse consequence measures. Studies that report difficulties identifying recidivists from program data seem to have focused more on measures of substance use (e.g., Anderson et al. 2000; Peck et al. 1994), whereas those that have had success in identifying recidivists have relied less on consumption measures and more on problem and consequence measures. Reporting more problems and consequences may be identifying those who experience more difficulty in modifying their behavior to avoid negative consequences of drinking and drug use, even when substance use measures are similar.

We have also seen important changes in measures from first to second attendance at the program. Recidivists showed changes in screening measures, reflecting both increases in more acute problems (on the RIASI-T measure) and decreases in problems reflecting more severe dependence (on the ADS measure); decreases in legal problems; increases in factor scores, suggesting a greater reporting or recognition of problems; and, finally, lower levels of alcohol use but higher levels of benzodiazepine use. These changes could be reflecting greater insight into personal problems and reduced denial, which have been identified as important prerequisites for constructive change in response to a remedial or treatment intervention (e.g., Wells-Parker et al. 2009). The transtheoretical model (Prochaska and DiClemente 1992), a very influential model of how individuals engage with treatment services, suggests that there are important stages that individuals pass through reflecting readiness to change. While the individuals in the recidivist group have distinguished themselves by being reconvicted of a drink-driving offense following program participation and thus might be considered to be reflecting a lack of readiness to change, the fact that this group has also returned to the program on a second occasion to reengage with the remedial process suggests 
that this group may in fact now be more ready to change. The differences seen between recidivists' first and second appearance may reflect this. However, we cannot know for certain which explanation is correct because these analyses do not include those who are recidivists and have chosen not to return to the program. Future analyses should endeavor to link these program data to driver record data to identify those who have recidivated and not returned to the program in order to determine how these two groups of recidivists differ.

Although the results of this study are subject to several important limitations, this study is one of the few to examine the characteristics of recidivist participants in a remedial program for convicted drink-drivers and the first study of changes that occur in those who recidivate and return to the program. As such, these results are of great interest and will be useful for understanding the nature of recidivist drivers and how best to identify and respond to them. In comparison to rates from other studies, the recidivism rates seen here appear low and indicative of a positive program effect. At first attendance, becoming a recidivist driver was predicted by elevations on measures suggestive of greater drinking problems and more adverse legal consequences. These results suggest that it may be possible to identify potential recidivists when they first participate in the program. If these individuals can be identified with reasonable accuracy, targeted program initiatives might be developed that reduce recidivism risk. Additional work to confirm these findings and better identify potential recidivists is therefore recommended. Factors identifying recidivist drivers at first and second attendance also differed. Notably, different risk and problem measures identified drivers at first attendance and second attendance. The fact that all substance problem measures significantly identified recidivists but at different stages in their engagement with the BOT program would seem to support the value of basing program assignment to education versus treatment on several potential problem indicators, as is currently the practice in BOT, rather than on a single indicator. The data also suggest that, in recidivist drivers who return to the program, there appear to be important changes from their first to their second participation. There are suggestions in the results that these changes are in a direction that would signify greater openness to behavior change in the direction promoted by the program. The nature and significance of these changes warrants further investigation, because they may identify further opportunities to promote positive behavior change in recidivist drink-drivers. 
AUTHORS' NOTE

A previous version of the manuscript was presented at the $25^{\text {th }}$ Canadian Association of Road Safety Professionals (CARSP) Conference, Ottawa, Ontario in 2015. 


\section{REFERENCES}

Anderson BJ, Snow RW, Wells-Parker E. Comparing the predictive validity of DUI risk screening instruments: development of validation standards. Addiction 2000; 95(6): 915-929.

Begg DJ, Langley JD, Stephenson S. Identifying factors that predict persistent driving after drinking, unsafe driving after drinking, and driving after using cannabis among young adults. Accident Anal. Prev. 2003; 35(5): 669675.

Brands B, Sproule B, Marshman J. Drugs and drug abuse. Addiction Research Foundation: Toronto; 1998.

Brown TG, Dongier M, Ouimet MC, Tremblay J, Chanut F, Legault L, Ng Ying Kin, NMK. Brief motivational interviewing for DWI recidivists who abuse alcohol and are not participating in DWI intervention: A randomized controlled trial. Alcohol. Clin. Exp. Res. 2010; 34(2): 292-301.

Campbell DT, Stanley JC. Experimental and quasi-experimental designs for research. Rand McNally: Chicago; 1967.

Darke S. Self-report among injecting drug users: a review. Drug Alcohol Depen. 1998; 51(3): 253-263.

Flam-Zalcman R, Mann RE, Stoduto G, Nochajski TH, Rush BR, Koski-Jännes A, Wickens CM, Thomas R, Rehm J. Evidence from regression-discontinuity analyses for beneficial effects of a criterion-based increase in alcohol treatment. Int. J. Meth. Psych. Res. 2013; 22(1): 59-70.

Greenfield SF, O’Leary G. Sex differences in marijuana use in the United States. Harvard Rev. Psychiat. 1999; 6(6): 297-303.

Health Canada, Best practices for the treatment and rehabilitation of driving while impaired offenders. Health Canada: Ottawa. 2004.

Lapham SC, C'de Baca J, Chang I, Hunt WC, Berger LR. Are drunk-driving offenders referred for screening accurately reporting their drug use?. Drug Alcohol Depen. 2002; 66(3): 243-253.

Macdonald S, Mann RE. Distinguishing causes and correlates of drinking and driving. Contemp. Drug Probl. 1996; 23: 259-290.

Mann RE, Anglin L, Wilkins K, Vingilis ER, Macdonald D, Sheu, W-J. Rehabilitation for convicted drinking drivers (second offenders): Effects on mortality. J. Stud. Alcohol 1994; 55(3): 372-374.

Mann RE, Leigh G, Vingilis E, De Genova, K. A critical review on the effectiveness of drinking-driving rehabilitation programmes. Accident Anal. Prev. 1983; 15(6): 441-461.

Mann RE, Macdonald S, Chipman ML, Adlaf EM, Anglin-Bodrug K, Zhao J. Identifying possible sources of bias introduced in traffic safety research: Comparison of blind linkage with volunteer clinical samples. In: T2002: Proceedings of the $16^{\text {th }}$ International Conference on Alcohol, Drugs and Traffic Safety. DR Mayhew, C Dussault (eds.). Société de l'Assurance Automobile du Québec : Montréal, Quebec, Canada, pp. 275-280 ; 2002.

Mann RE, Rootman DB, Shuggi R, Adlaf E. Assessing consequences of alcohol and drug abuse in a drinking driving population. Drug-Educ. Prev. Polic. 2006; 13(4): 313-326.

Mann RE, Stoduto G, Flam Zalcman R, Nochajski TH, Hall L, Dill P, Wells-Parker E. Examining factors in the Research Institute on Addictions Self-Inventory (RIASI): Associations with alcohol use and problems at assessment and follow-up. Int. J. Environ. Res. Public Health 2009; 6(11): 2898-2918. 
Mann RE, Vingilis ER, Stewart K. Programmes to change individual behaviour: Education and rehabilitation in the prevention of drinking and driving. In: The social control of drinking and driving. MD Laurence, JR Snortum, FE Zimring (eds). University of Chicago Press: Chicago, pp. 248-269; 1988.

Marowitz LA. Predicting DUI recidivism: Blood alcohol concentration and driver record factors. Accident Anal. Prev. 1998; 30(4): 545-554.

Naimi TS, Brewer RD, Mokdad A, Denny C, Serdula MK, Marks JS. Binge drinking among US adults. JAMA. 2003; 289(1): 70-75.

Nochajski TH. Training manual for the Research Institute on Addictions Self Inventory (RIASI)-Revised. Research Institute on Addictions: Buffalo, NY; 2002.

Nochajski TH, Miller BA, Augustino DK, Kramer R. Use of non-obvious indicators for screening of DWI offenders. In: Alcohol, drugs and traffic safety - T'95. CN Kloeden, AJ McLean (eds.). NHMRC Road Accident Research Unit, the University of Adelaide: Adelaide, Australia, pp. 449-454; 1995.

Nochajski TH, Stasiewicz PR. Relapse to driving under the influence (DUI): A review. Clin. Psychol. Rev. 2006; 26(2): 179-195.

Peck RC, Arstein-Kerslake GW, Helander CJ. Psychometric and biographical correlates of drunk-driving recidivism and treatment program compliance. J. Stud. Alcohol 1994; 55(6): 667-678.

Prochaska JO, DiClemente CC. Stages of change in the modification of problem behaviors. Prog. Behav. Modific. 1992; 28: 183-218.

Rauch WJ, Zador PL, Ahlin EM, Howard JM, Frissell KC, Duncan GD. Risk of alcohol-impaired driving recidivism among first offenders and multiple offenders. Am. J. Public Health 2010; 100(5): 919-924.

Robertson AA, Gardner S, Xu X, Costello $\mathrm{H}$. The impact of remedial intervention on 3-year recidivism among firsttime DUI offenders in Mississippi. Accident Anal. Prev. 2009; 41(5): 1080-1086.

Sharpley J, Flam Zalcman R, Mann RE, Brands B, Stoduto G. Back on Track report no. 7: Outcome evaluation of the Back on Track program: Program impact on alcohol and drug use and related problems. Centre for Addiction and Mental Health: Toronto; 2007.

Skinner HA. The Drug-Abuse Screening Test. Addict. Behav. 1982; 7(4): 363-371.

Skinner HA, Horn JL. Alcohol Dependence Scale (ADS) user's guide. Addiction Research Foundation: Toronto; 1984.

Smart RG. Back on Track report no. 10: Participation in impaired driving rehabilitation: Can it be improved. Centre for Addiction and Mental Health: Toronto; 2007.

Weinrath MMT. Explanation of drunk driving recidivism: An exploratory analysis [unpublished $\mathrm{PhD}$ thesis]. Department of Sociology, University of Alberta; 1997.

Wells-Parker E, Bangert-Drowns R, McMillen R, Williams M. Final results from a meta-analysis of remedial interventions with drink-drive offenders. Addiction 1995; 90(7): 907-926.

Wells-Parker ES, Mann RE, Dill PL, Stoduto G, Shuggi R, Cross GW. Negative affect and drinking drivers: a review and conceptual model linking dissonance, efficacy and negative affect to risk and motivation for change.

Curr. Drug Abuse Rev. 2009; 2(2): 115-126. 
Wickens CM, Mann RE, Stoduto G, Butters JE, Ialomiteanu A, Smart RG. Does gender moderate the relationship between driver aggression and its risk factors? Accident Anal. Prev. 2012; 45: 10-18.

Winters KC, Stinchfield RD, Henly GA, Schwartz RH. Validity of adolescent self-report of alcohol and other drug involvement. Int. J. Addict. 1990; 25(11A): 1379-1395. 
Table 1. Client demographics: Differences between recidivist and nonrecidivist groups and between first and second attendance by recidivists.

\begin{tabular}{|c|c|c|c|c|c|c|c|c|c|}
\hline \multirow[t]{2}{*}{ Variables } & \multirow{2}{*}{$\begin{array}{c}\text { Group } 1 \\
\text { non- } \\
\text { recidivists } \\
(\mathrm{N}=58,548) \\
(\%)\end{array}$} & \multirow{2}{*}{$\begin{array}{c}\text { Group } 2 \\
\text { recidivists - } \\
\quad \text { first } \\
\text { assessment } \\
(\mathrm{N}=586)(\%)\end{array}$} & \multirow{2}{*}{$\begin{array}{c}\text { Group } 3 \\
\text { recidivists - } \\
\text { second } \\
\text { assessment } \\
(\mathrm{N}=586)(\%)\end{array}$} & \multicolumn{2}{|c|}{$\begin{array}{l}\text { Group } \\
1 \text { vs. } 2 \\
\end{array}$} & \multicolumn{2}{|c|}{$\begin{array}{l}\text { Group } \\
1 \text { vs. } 3 \\
\end{array}$} & \multicolumn{2}{|c|}{$\begin{array}{l}\text { Group } \\
2 \text { vs. } 3 \\
\end{array}$} \\
\hline & & & & $X^{2}$ & $P$ & $X^{2}$ & $P$ & $X^{2}$ & $P$ \\
\hline \multicolumn{10}{|l|}{ Age (\%) } \\
\hline$<30$ & 26.82 & 31.91 & 19.28 & 13.98 & 0.007 & 27.10 & 0.000 & 38.59 & 0.000 \\
\hline $30-44$ & 38.50 & 39.76 & 38.05 & & & & & & \\
\hline $45-59$ & 28.33 & 24.23 & 33.79 & & & & & & \\
\hline $60-74$ & 6.03 & 3.92 & 8.02 & & & & & & \\
\hline$>75$ & 0.33 & 0.17 & 0.85 & & & & & & \\
\hline \multicolumn{10}{|l|}{ Gender $(\%)$} \\
\hline Female & 12.96 & 7.51 & 7.51 & 15.36 & 0.000 & 15.36 & 0.000 & 0.00 & 1.000 \\
\hline Male & 87.04 & 92.49 & 92.49 & & & & & & \\
\hline \multicolumn{10}{|l|}{ Marriage Status (\%) } \\
\hline married & 43.35 & 37.54 & 44.18 & 8.19 & 0.017 & 7.48 & 0.024 & 8.01 & 0.018 \\
\hline single & 37.93 & 41.13 & 33.39 & & & & & & \\
\hline previously & 18.72 & 21.33 & 22.43 & & & & & & \\
\hline \multicolumn{10}{|l|}{ Income $(\%)$} \\
\hline$<\$ 20000$ & 24.45 & 24.43 & 20.32 & 2.20 & 0.531 & 16.38 & 0.001 & 10.07 & 0.018 \\
\hline$\$ 20000-49999$ & 52.32 & 51.14 & 51.87 & & & & & & \\
\hline$\$ 50000-79999$ & 17.10 & 19.16 & 18.00 & & & & & & \\
\hline$\$ 80000$ and above & 6.12 & 5.27 & 9.80 & & & & & & \\
\hline \multicolumn{10}{|l|}{ Employment (\%) } \\
\hline employed full-time & 70.39 & 73.46 & 70.62 & 5.64 & 0.130 & 13.66 & 0.003 & 15.42 & 0.001 \\
\hline employed part-time & 5.73 & 6.68 & 3.09 & & & & & & \\
\hline not employed/ student & 19.58 & 16.44 & 19.76 & & & & & & \\
\hline retired & 4.30 & 3.42 & 6.53 & & & & & & \\
\hline \multicolumn{10}{|l|}{ Education $(\%)$} \\
\hline unfinished high school & 26.04 & 25.43 & 24.74 & 4.19 & 0.123 & 2.25 & 0.325 & 5.67 & 0.059 \\
\hline high school & 43.53 & 47.44 & 41.98 & & & & & & \\
\hline college/university & 30.43 & 27.13 & 33.28 & & & & & & \\
\hline \multicolumn{10}{|l|}{ Assigned to: $(\%)$} \\
\hline Education & 72.10 & 71.84 & 63.31 & 0.02 & 0.892 & 22.22 & 0.000 & 9.74 & 0.002 \\
\hline Treatment & 27.90 & 28.16 & 36.69 & & & & & & \\
\hline
\end{tabular}


Table 2. Screening scores and previous convictions: Mean differences between recidivist and nonrecidivist groups and between first and second attendance by recidivists.

\begin{tabular}{|c|c|c|c|c|c|c|c|c|c|}
\hline \multirow[t]{2}{*}{ Variables } & \multirow{2}{*}{$\begin{array}{c}\text { Group } 1 \\
\text { non- } \\
\text { recidivists } \\
\text { Mean }(\mathrm{SD}) \\
(\mathrm{N}=58,548)\end{array}$} & \multirow{2}{*}{$\begin{array}{l}\text { Group } 2 \\
\text { recidivists - } \\
\text { first assessment } \\
\text { Mean }(\mathrm{SD}) \\
(\mathrm{N}=586)\end{array}$} & \multirow{2}{*}{$\begin{array}{c}\text { Group } 3 \\
\text { recidivists - } \\
\text { second assessment } \\
\text { Mean }(\mathrm{SD}) \\
(\mathrm{N}=586)\end{array}$} & \multicolumn{2}{|c|}{$\begin{array}{l}\text { Group } \\
1 \text { vs. } 2\end{array}$} & \multicolumn{2}{|c|}{$\begin{array}{l}\text { Group } \\
1 \text { vs. } 3\end{array}$} & \multicolumn{2}{|c|}{$\begin{array}{l}\text { Group } \\
2 \text { vs. } 3\end{array}$} \\
\hline & & & & $t$ & $\operatorname{Pr}>|t|$ & $t$ & $\operatorname{Pr}>|t|$ & $t$ & $\operatorname{Pr}>|t|$ \\
\hline RIASI-T & $6.92(4.95)$ & $7.11(5.18)$ & $7.91(5.53)$ & 0.91 & 0.360 & 4.82 & 0.000 & -3.55 & 0.000 \\
\hline RIASI-R & $3.30(2.16)$ & $3.36(2.21)$ & $3.60(2.22)$ & 0.66 & 0.510 & 3.35 & 0.001 & -2.44 & 0.015 \\
\hline ADS & $1.78(3.36)$ & $2.23(3.42)$ & $1.77(3.61)$ & 3.22 & 0.001 & -0.04 & 0.967 & 2.84 & 0.005 \\
\hline DAST & $0.31(1.17)$ & $0.40(1.39)$ & $0.24(1.01)$ & 1.87 & 0.064 & -1.58 & 0.114 & 2.82 & 0.005 \\
\hline DWI convictions & $1.35(0.74)$ & $1.24(0.60)$ & $2.16(0.63)$ & -3.88 & 0.000 & 26.32 & 0.000 & -39.70 & 0.000 \\
\hline
\end{tabular}


Table 3. Consequences of substance use (ACSUS): Mean differences between recidivist and nonrecidivist groups and between first and second attendance by recidivists.

\begin{tabular}{|c|c|c|c|c|c|c|c|c|c|}
\hline \multirow{2}{*}{ Variables } & \multirow{2}{*}{$\begin{array}{c}\text { Group } 1 \\
\text { non- } \\
\text { recidivists } \\
\text { Mean }(\mathrm{SD}) \\
(\mathrm{N}=58,548)\end{array}$} & \multirow{2}{*}{$\begin{array}{c}\text { Group } 2 \\
\text { recidivists - } \\
\quad \text { first } \\
\text { assessment } \\
\text { Mean }(\mathrm{SD}) \\
(\mathrm{N}=586)\end{array}$} & \multirow{2}{*}{$\begin{array}{c}\text { Group } 3 \\
\text { recidivists - } \\
\text { second } \\
\text { assessment } \\
\text { Mean }(\mathrm{SD}) \\
(\mathrm{N}=586)\end{array}$} & \multicolumn{2}{|c|}{$\begin{array}{l}\text { Group } \\
1 \text { vs. } 2 \\
\end{array}$} & \multicolumn{2}{|c|}{$\begin{array}{l}\text { Group } \\
1 \text { vs. } 3 \\
\end{array}$} & \multicolumn{2}{|c|}{$\begin{array}{l}\text { Group } \\
2 \text { vs. } 3\end{array}$} \\
\hline & & & & $t$ & $\operatorname{Pr}>|t|$ & $t$ & $\operatorname{Pr}>|t|$ & $t$ & $\operatorname{Pr}>|t|$ \\
\hline Health problems & $02(0$ & $0.02(0.17)$ & $0.04(0.27)$ & -0.45 & 0.656 & 2.08 & 0.038 & -1.67 & 0.096 \\
\hline Memory Loss & 02 & 03 & $.14)$ & 2.01 & 0.044 & 0.20 & 0.844 & 1.18 & 0.240 \\
\hline Mood Changes & $0.06(0.24)$ & $0.07(0.27)$ & $0.06(0.24)$ & 1.70 & 0.089 & -0.01 & 0.994 & 1.18 & 0.239 \\
\hline $\begin{array}{l}\text { Relationship } \\
\text { problems }\end{array}$ & $0.03(0.18)$ & $0.05(0.23)$ & $0.04(0.25)$ & 2.54 & 0.011 & 2.31 & 0.021 & 0.12 & 0.901 \\
\hline Aggression problems & $0.01(0.11)$ & $0.01(0.14)$ & $0.01(0.07)$ & 0.44 & 0.659 & -1.04 & 0.301 & 1.07 & 0.285 \\
\hline Work problems & $0.01(0.14)$ & $0.02(0.15)$ & $0.01(0.12)$ & 0.40 & 0.690 & -0.47 & 0.639 & 0.24 & 0.809 \\
\hline Legal problems & $0.26(0.67)$ & $0.34(0.75)$ & $0.04(0.29)$ & 2.94 & 0.003 & -7.87 & 0.000 & 9.28 & 0.000 \\
\hline Financial problems & $0.02(0.16)$ & $0.03(0.22)$ & $0.02(0.15)$ & 1.89 & 0.058 & -0.10 & 0.923 & 1.30 & 0.195 \\
\hline
\end{tabular}


Table 4. RIASI factors scores: Mean differences between recidivist and nonrecidivist groups and between first and second attendance by recidivists.

\begin{tabular}{|c|c|c|c|c|c|c|c|c|c|}
\hline \multirow[t]{2}{*}{ Variables } & \multirow[t]{2}{*}{ 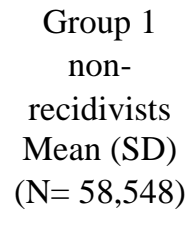 } & \multirow[t]{2}{*}{$\begin{array}{c}\text { Group } 2 \\
\text { recidivists - } \\
\text { first assessment } \\
\text { Mean (SD) } \\
(\mathrm{N}=586)\end{array}$} & \multirow{2}{*}{$\begin{array}{l}\text { Group } 3 \\
\text { recidivists - } \\
\text { second } \\
\text { assessment } \\
\text { Mean }(\mathrm{SD}) \\
(\mathrm{N}=586)\end{array}$} & \multicolumn{2}{|c|}{$\begin{array}{l}\text { Group } \\
1 \text { vs. } 2 \\
\end{array}$} & \multicolumn{2}{|c|}{$\begin{array}{l}\text { Group } \\
1 \text { vs. } 3 \\
\end{array}$} & \multicolumn{2}{|c|}{$\begin{array}{l}\text { Group } \\
2 \text { vs. } 3 \\
\end{array}$} \\
\hline & & & & $t$ & $\operatorname{Pr}>|t|$ & $t$ & $\operatorname{Pr}>|t|$ & $t$ & $\operatorname{Pr}>|t|$ \\
\hline Negative affect & $.14(1.53)$ & $1.25(1.59)$ & $1.30(1.82)$ & 1.71 & 0.088 & 2.45 & 0.014 & -0.63 & 0.527 \\
\hline Sensation seeking & $0.44(0.73)$ & $0.45(0.79)$ & $0.44(0.70)$ & 0.41 & 0.685 & 0.07 & 0.945 & 0.31 & 0.755 \\
\hline Alcohol quantity & $1.48(1.45)$ & $1.51(1.47)$ & $1.53(1.47)$ & 0.45 & 0.652 & 0.82 & 0.413 & -0.31 & 0.754 \\
\hline Social desirability scale & $0.48(0.74)$ & $0.48(0.72)$ & $0.46(0.73)$ & 0.04 & 0.972 & -0.52 & 0.602 & 0.50 & 0.620 \\
\hline High-risk lifestyle & $1.17(1.15)$ & $1.14(1.17)$ & $1.32(1.21)$ & -0.61 & 0.543 & 3.21 & 0.001 & -3.53 & 0.000 \\
\hline Alcohol consequences & $0.58(1.13)$ & $0.65(1.29)$ & $0.94(1.38)$ & 1.51 & 0.131 & 7.57 & 0.000 & -4.34 & 0.000 \\
\hline Interpersonal competence & $0.54(0.82)$ & $0.57(0.89)$ & $0.75(1.04)$ & 0.94 & 0.346 & 6.35 & 0.000 & -3.73 & 0.000 \\
\hline Family history & $0.53(0.70)$ & $0.51(0.71)$ & $0.58(0.72)$ & -0.65 & 0.518 & 1.58 & 0.114 & -2.10 & 0.036 \\
\hline
\end{tabular}


Table 5. Number of days of substance use: Mean differences between recidivist and nonrecidivist groups and between first and second attendance by recidivists.

\begin{tabular}{|c|c|c|c|c|c|c|c|c|c|}
\hline \multirow[t]{2}{*}{ Variables } & \multirow[t]{2}{*}{$\begin{array}{c}\text { Group 1 } \\
\text { non- } \\
\text { recidivists } \\
\text { Mean (SD) } \\
(\mathrm{N}=58,548)\end{array}$} & \multirow{2}{*}{$\begin{array}{c}\text { Group } 2 \\
\text { recidivists - } \\
\quad \text { first } \\
\text { assessment } \\
\text { Mean }(\mathrm{SD}) \\
(\mathrm{N}=586)\end{array}$} & \multirow{2}{*}{$\begin{array}{c}\text { Group } 3 \\
\text { recidivists - } \\
\text { second } \\
\text { assessment } \\
\text { Mean }(\mathrm{SD}) \\
(\mathrm{N}=586)\end{array}$} & \multicolumn{2}{|c|}{$\begin{array}{l}\text { Group } \\
1 \text { vs. } 2\end{array}$} & \multicolumn{2}{|c|}{$\begin{array}{l}\text { Group } \\
1 \text { vs. } 3\end{array}$} & \multicolumn{2}{|c|}{$\begin{array}{l}\text { Group } \\
2 \text { vs. } 3\end{array}$} \\
\hline & & & & $t$ & $\operatorname{Pr}>|t|$ & $t$ & $\operatorname{Pr}>|t|$ & $t$ & $\operatorname{Pr}>|t|$ \\
\hline Drinks per drinking day & $3.16(2.96)$ & $3.35(3.00)$ & $2.56(3.05)$ & 1.60 & 0.109 & -4.86 & 0.000 & 5.16 & 0.000 \\
\hline Alcohol & $12.77(16.96)$ & $11.61(14.81)$ & $10.39(17.46)$ & -1.65 & 0.098 & -3.38 & 0.001 & 1.54 & 0.124 \\
\hline Cocaine & $0.02(0.47)$ & $0.01(0.09)$ & $0.05(0.71)$ & -0.52 & 0.603 & 1.40 & 0.162 & -1.30 & 0.195 \\
\hline Amphetamines & $0.04(1.83)$ & $0.01(0.22)$ & $0.00(0.00)$ & -0.43 & 0.668 & -0.59 & 0.558 & 1.30 & 0.194 \\
\hline Cannabis & $1.26(7.65)$ & $1.16(7.17)$ & $0.78(6.34)$ & -0.32 & 0.746 & -1.52 & 0.129 & 1.07 & 0.284 \\
\hline Benzodiazepines & $1.45(10.75)$ & $0.71(7.37)$ & $2.80(15.34)$ & -1.67 & 0.096 & 3.00 & 0.003 & -3.14 & 0.002 \\
\hline Barbiturates & $0.09(2.65)$ & $0.00(0.00)$ & $0.15(3.68)$ & -0.83 & 0.408 & 0.55 & 0.579 & -1.00 & 0.318 \\
\hline Heroin & $0.01(0.83)$ & $0.00(0.00)$ & $0.00(0.00)$ & -0.22 & 0.823 & -0.22 & 0.823 & . & . \\
\hline Prescription opioids & $1.89(11.74)$ & $1.02(8.16)$ & $2.11(12.70)$ & -1.78 & 0.075 & 0.45 & 0.652 & -1.87 & 0.062 \\
\hline Codeine & $0.19(3.27)$ & $0.02(0.25)$ & $0.17(2.71)$ & -1.23 & 0.220 & -0.09 & 0.929 & -1.36 & 0.173 \\
\hline Hallucinogens & $0.00(0.08)$ & $0.00(0.06)$ & $0.00(0.04)$ & 0.49 & 0.621 & 0.00 & 0.998 & 0.58 & 0.564 \\
\hline Glue & $0.00(0.17)$ & $0.00(0.00)$ & $0.00(0.00)$ & -0.10 & 0.918 & -0.10 & 0.918 & & \\
\hline Tobacco & $49.91(43.63)$ & 50.97 (43.29) & $48.10(43.71)$ & 0.58 & 0.560 & -1.00 & 0.318 & 1.85 & 0.065 \\
\hline Other & $3.91(18.07)$ & $4.04(18.36)$ & $5.08(20.72)$ & 0.16 & 0.870 & 1.55 & 0.121 & -1.09 & 0.274 \\
\hline
\end{tabular}

